\title{
Establishment of in vitro Culture of Rubber (Hevea brasiliensis) from Field-derived Explants: Effective Role of Silver Nanoparticles in Reducing Contamination and Browning
}

\author{
Moradpour $\mathbf{M}^{1^{*}}$, Aziz MA ${ }^{1,2}$ and Abdullah SNA ${ }^{1,2}$
}

${ }^{1}$ Laboratory of Plantation Crops, Institute of Tropical Agriculture, Universiti Putra Malaysia, 43300 Serdang, Selangor Darulehasan, Malaysia

${ }^{2}$ Department of Agriculture Technology, Faculty of Agriculture, Universiti Putra Malaysia, 43300 Serdang, Selangor Darulehasan, Malaysia

\begin{abstract}
The development of in vitro methods to produce high quality clonal planting materials of $\mathrm{c}$ for replanting and new planting is highly essential. The establishment of in vitro cultures of challenging woody plant species like $\mathrm{H}$. brasiliensis has frequently been hampered by persistent microbial contamination, phenolic production, phase change and low response to media. Therefore, the overall goal of this study was to establish an efficient in vitro propagation method for $\mathrm{H}$. brasiliensis through solving those persistent problems. In determining the most suitable method of reducing explant contamination, different concentrations of sodium hypochlorite, mercuric chloride and nano silver (NS) at different immersion times were assessed on explants derived from three physiological leaf stages (bronze, light green and stable green leaf stages) of preculture and non-preculture treated plants. The highest percentage of survival $(94.44 \%)$ was from explants derived from the light green leaf stage of preculture treated plants immersed in $10 \mathrm{ppm}$ NS for 20 min. Different types of adsorbents which were silver nitrate, activated charcoal and NS were assessed in controlling browning of in vitro cultures of $\mathrm{H}$. brasiliensis. NS at $4 \mathrm{ppm}$ significantly produced the highest percentage of explant survival $(87.03 \%)$ with a low percentage of browning (10\%). In determining the most suitable medium for in vitro culture of $\mathrm{H}$. brasiliensis explants, Murashige and Skoog (MS) medium, Woody Plant medium (WPM) and Enjalric and Carron (MB) medium in combination with $3 \%, 6 \%$ and $9 \%$ sucrose concentrations were assessed. After 16 weeks of culture, the highest percentage of shoot formation $(80 \%)$ was on MB medium supplemented with $6 \%$ sucrose.
\end{abstract}

Keywords: Micropropagation; Hevea brasiliensis; Sterilization; Phenolic compounds; Hevea leaf development

\section{Introduction}

Hevea brasiliensis is commonly the rubber tree, is a tree belonging to the family Euphorbiaceae. It is the most economically important member of the genus Hevea. It is of major economic importance because the milky latex extracted from the tree is the primary source of natural rubber. $\mathrm{H}$. brasiliensis is still traditionally propagated by grafting clonal axillary buds onto unselected seedlings as stock plant to maintain intraclonal heterogeneity for both vigour and productivity [1]. New methods of propagation are highly recommended in order to eliminate the possible incompatibility between rootstock and scion, as well as to reduce the cost and time required for plant production. Micropropagation is a promising technique for large scale multiplication of selected clones. It has the advantages of small space requirements and reduced costs when compared to conventional vegetative propagation techniques. Although gross experimentation was conducted in the past for standardizing in vitro technologies in rubber, there had been many setbacks in commercializing these procedures [2,3]. A number of aspects inherent in the explant tissue are responsible for the delay in commercialization. These include: (i) the release of phenols; (ii) contamination by bacteria and fungi; (iii) their recalcitrant status; (iv) reduced axillary branches; (v) lack of sufficient juvenility; and above all (vi) increased sensitivity of in vitroraised plantlets towards environmental attributes. There are some methods and chemicals available to control in vitro contamination. The efficiency of some of these methods is low, and some of the chemicals are too toxic. The laboratory-based sterilization of explant cannot fulfil its potential to control in vitro contamination until it includes reference to the natural environment in which plants evolved. In fact, interaction with the environment is a key factor affecting the establishment of explants in plant tissue culture. Previous studies have shown that physiological aging negatively affects the micropropagation capacity of $H$. brasiliensis from microcuttings [4,5]. This phase change phenomenon has been observed in many studies and is associated with a noticeable decline in the potential of micropropagation or somatic embryogenesis of most arborescent species [6-9]. The second difficulty in in vitro establishment of Hevea species is the rapid browning and/ or necrosis of the explants. These problems are partly caused by oxidation of polyphenols which are abundant in Hevea species [10]. Also, inhibition of shoot organogenesis and necrosis of the explants are associated with considerable leaking of exudates into the culture medium [11]. There are no preliminary reports on reduction of browning in this plant material. To optimise an efficient tissue culture method for Hevea rubber, explant preparation is one of the important steps that need to be given attention in order to overcome the problem of microbial contamination and browning. Besides understanding the mother plant and its interaction with the environment it is also important that new types of sterilants are introduced to combat the problems faced during in vitro culture establishment. The antibacterial effects of Ag salts have been noticed since antiquity [12]. Nano silver is a new and non-toxic material which shows high capability in eliminating microorganisms, e.g., fungus, bacteria and viruses through the release of tiny particles of silver that could destroy the microorganisms [13].

*Corresponding authors: Mahdi Moradpour, Laboratory of Plantation Crops, Institute of Tropical Agriculture, Universiti Putra Malaysia, 43300 Serdang, Selangor Darulehasan, Malaysia, Tel: 0389471043; ; E-mail: maherandmr@gmail.com

Received September 29, 2015; Accepted May 05, 2016; Published May 12, 2016

Citation: Moradpour M, Aziz MA, Abdullah SNA (2016) Establishment of in vitro Culture of Rubber (Hevea brasiliensis) from Field-derived Explants: Effective Role of Silver Nanoparticles in Reducing Contamination and Browning. J Nanomed Nanotechnol 7: 375. doi:10.4172/2157-7439.1000375

Copyright: (c) 2016 Moradpour M, et al. This is an open-access article distributed under the terms of the Creative Commons Attribution License, which permits unrestricted use, distribution, and reproduction in any medium, provided the original author and source are credited. 
Citation: Moradpour M, Aziz MA, Abdullah SNA (2016) Establishment of in vitro Culture of Rubber (Hevea brasiliensis) from Field-derived Explants: Effective Role of Silver Nanoparticles in Reducing Contamination and Browning. J Nanomed Nanotechnol 7: 375. doi:10.4172/21577439.1000375

Page 2 of 7

The detrimental effects of nano silver have been shown on more than six hundred microorganisms [14]. There are no preliminary reports on reduction of contamination and browning using silver nanoparticles in in vitro culture of Hevea. This study attempts to establish an efficient in vitro culture of $H$. brasiliensis from field-derived explants through determining the most suitable method of reducing contamination and browning, as well as determining a suitable medium for promoting shoot formation (Figure 1)

\section{Materials and Methods}

\section{Plant materials}

One to two year-old grafted plants of $H$. brasiliensis clone RRIM 2025, grown in polybags were obtained from Rubber Industry Smallholder Development Authority (RISDA) nursery in Jelebu, Negri Sembilan, Malaysia. The plants were maintained in the Department of Agriculture Technology, Faculty of Agriculture, Universiti Putra Malaysia. The plants were regularly pruned to enhance lateral shoot development for use in this study. In order to assess the effects of environmental conditions on the degree of microbial infection of the Hevea tissues, the grafted plants were divided into two groups, with preculture treatment and without preculture treatment (control). The preculture treatment was applied by spraying the plants with a mixture consisting of $0.1 \%$ white oil, $0.2 \%$ benomyl and $90 \mathrm{mg} \mathrm{L}^{-1}$ Welgro fertilizer. Then, explants consisting of shoot tips and axillary buds were taken from branches at different leaf developmental (physiological) stages (Figure 2) indicated by the leaf colour: (1) bronze leaf stage, (2) light green leaf stage and (3) stable green leaf stage of the preculture and non-preculture treated plants.

Effects of sterilant type and concentration, preculture treatment and leaf developmental stage on overcoming contamination of $\boldsymbol{H}$. brasiliensis explants

Sodium hypochlorite $(\mathrm{NaOCl})$ at $10 \%, 20 \%, 30 \%$ and $40 \%$, mercuric chloride $\left(\mathrm{HgCl}_{2}\right)$ at $0.1 \%$ and $0.2 \%$ and $\mathrm{NS}$ at $2.5,5,10,50$ and $200 \mathrm{ppm}$ were freshly prepared prior to use and dispensed in jam jars. Hevea explants were harvested from the bronze, light green and stable green leaf stage of both preculture treated plants and the control. The explants were harvested at 10-12 days after pruning for the bronze coloured leaf stage, 23-25 days after pruning for the light green leaf stage and 40-45 day after pruning for the stable green leaf stage. All expanded leaves were removed and the explants were excised into $1 \mathrm{~cm}$ pieces and washed thoroughly until all latex and rubber particles were removed. The explants were washed in $70 \% \mathrm{v} / \mathrm{v}$ ethanol for 30 seconds. Then, the explants were immersed in the different concentrations of $\mathrm{NaOCl}$ for 10, 20 and $30 \mathrm{~min}$, in $\mathrm{HgCl}_{2}$ for 5 and $10 \mathrm{~min}$ and in NS for 5 , 20 and $60 \mathrm{~min}$, added with a few drops of Tween-20. They were shaken throughout in the sterilant and washed 5-6 times with sterile distilled water. Explants without exposure to the sterilants were considered as the control. Finally, the cut ends of the explants were trimmed and the explants were cultured on $40 \mathrm{~mL}$ of MS medium containing 3\% sucrose, $0.3 \%$ Gelrite without hormone supplementation. Each treatment combination was repeated three times and each replication per treatment consisted of 6 explants. At the end of 4 weeks of culture, the percentage of explant survival was recorded.

\section{Control of browning of in vitro cultures of $\mathrm{H}$. brasiliensis}

To reduce the occurrence of browning of cultures, different adsorbents which were silver nitrate $\left(\mathrm{AgNO}_{3}\right)$ activated charcoal (AC) and NS at various concentrations were evaluated. The explants were derived from the light green leaf stage of preculture treated plants and sterilized with $10 \mathrm{ppm}$ NS for 20 min (best sterilization procedure determined above). MS basal medium was supplemented with 2, 4 and $6 \mathrm{ppm}$ of $\mathrm{AgNO}_{3} ; 1,3$ and $5 \mathrm{ppm}$ of $\mathrm{AC}$ and 4, 8, 12 and $16 \mathrm{ppm}$ of NS. The explants were cultured on $10 \mathrm{~mL}$ aliquots of the respective media contained in $25 \times 100 \mathrm{~mm}$ vials. Explants placed on hormone-free MS medium were considered as the control. Each treatment was replicated three times and each replication per treatment consisted of 6 explants. The percentage of browning and percentage of explant survival were recorded at the end of 5 weeks of culture.

\section{Effects of basal medium and sucrose concentration on shoot induction}

Low response to media is another hindrance in the tissue culture of $H$. brasiliensis explants. In this experiment, full strength of WPM, MS and MB media were prepared in combination with $3 \%, 6 \%$ and $9 \%$ sucrose. The explants were derived from the light green leaf stage of preculture treated plants and sterilized with $10 \mathrm{ppm}$ NS for $20 \mathrm{~min}$ (best sterilization procedure determined above). To overcome browning, the media were incorporated with $0.5 \% \mathrm{AC}$ (best adsorbent treatment determined above). The explants were cultured on $40 \mathrm{~mL}$ of solid medium contained in $100 \mathrm{~mL}$ Pyrex Erlenmeyer flasks. Each treatment

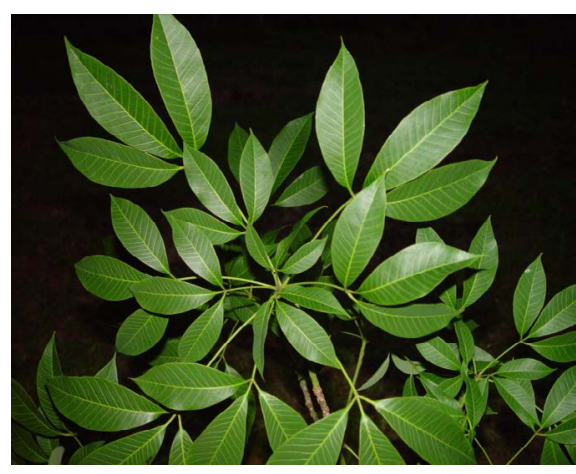

Figure 1: Hevea brasiliensis.

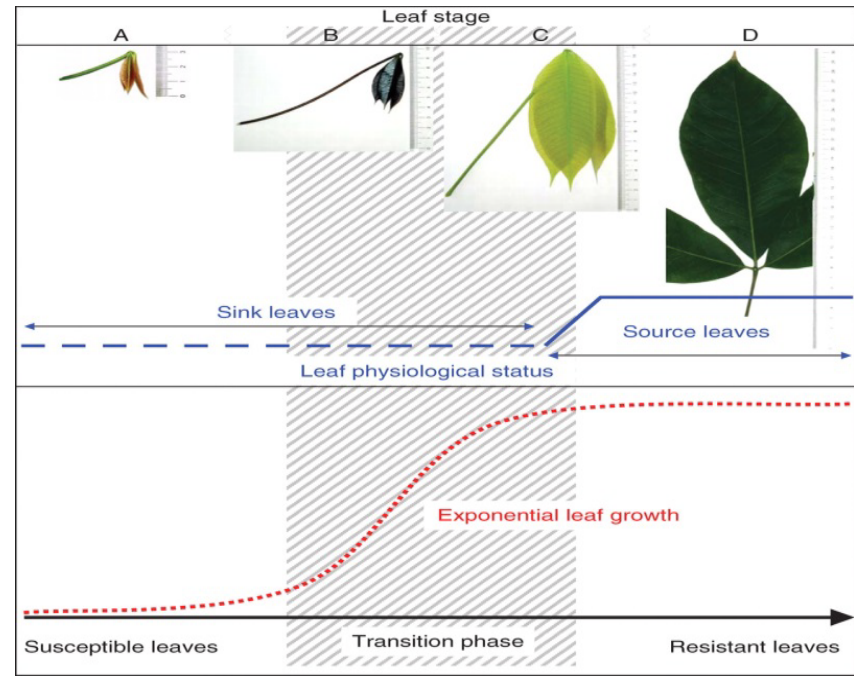

Figure 2: Relationship between exponential leaf growth, transition phase from completely susceptible leaf stage to completely resistant leaf stage, and the short physiological step from sink to source leaves. This qualitative comparison attempts to visualize the different developmental processes that turn a susceptible rubber tree leaf into a completely age-resistant organ (Lieberei, 2007) 
Citation: Moradpour M, Aziz MA, Abdullah SNA (2016) Establishment of in vitro Culture of Rubber (Hevea brasiliensis) from Field-derived Explants: Effective Role of Silver Nanoparticles in Reducing Contamination and Browning. J Nanomed Nanotechnol 7: 375. doi:10.4172/21577439.1000375

Page 3 of 7

was replicated three times and each replication per treatment consisted of 18 explants. The explants were subcultured on fresh medium of the same constituents at 4 -week intervals. The percentage of shoot formation was recorded at the end of 16 weeks of culture.

\section{Culture conditions}

Cultures were incubated on racks in an air-conditioned culture room with the temperature maintained at $25 \pm 2{ }^{\circ} \mathrm{C}$ and a relative humidity of 50 to $70 \%$. Illumination was provided by 80 watt fluorescent lamps (Philips TL $80 \mathrm{~W} / 55 \mathrm{~T}$ ) at an intensity of $45 \mu \mathrm{mol} \mathrm{m}^{-2} \mathrm{~s}^{-1}$ for 16 hours photoperiod.

\section{Statistical analysis}

Statistical analyses were performed using the statistical analysis system (SAS) program (Version 9.2). Data were subjected to one-way analysis of variance (ANOVA) for mean comparison and significant differences were calculated according to Duncan's multiple range test (DMRT). Differences at $P=0.05$ were considered statistically significant.

\section{Results}

\section{Effects of $\mathrm{NaOCl}$ in combination with preculture treatment and leaf developmental stage}

Table 1 shows the effects of different treatments of $\mathrm{NaOCl}$ on survival of explants derived from the three leaf developmental stages of preculture and non-preculture treated plants. It is obvious that explants derived from the three leaf developmental stages of preculture treated plants generally showed moderate to high percentage of explant survival. Increase in the concentration of $\mathrm{NaOCl}$ and duration of immersion decreased the percentage of survival of explants taken from all leaf developmental stages. Explants from the bronze leaf stage of preculture treated plants showed up to $79.62 \%$ survival after sterilization in $20 \% \mathrm{NaOCl}$ for $20 \mathrm{~min}$, while explants from the bronze leaf stage of non-preculture treated plants exhibited a maximum of $57.40 \%$ survival after sterilization in $20 \% \mathrm{NaOCl}$ for $20 \mathrm{~min}$. Meanwhile, explants from the stable green leaf stage of preculture treated plants exhibited a maximum of $62.96 \%$ explant survival after sterilization in $20 \% \mathrm{NaOCl}$ for $20 \mathrm{~min}$, while explants from the stable green leaf stage of non-preculture treated plants attained the highest survival of $51.85 \%$ also after sterilization in $20 \% \mathrm{NaOCl}$ for 20 min as well. Overall, $\mathrm{NaOCl}$ was effective to some extent the increase in immersion time resulted in loss of explants due to browning followed by leaching of chlorophyll from the explants. In order to use $\mathrm{NaOCl}$ as a sterilizing agent for $H$. brasiliensis explants, it is therefore recommended to take explants from the bronze leaf stage of preculture treated plants and sterilized with $20 \%$ of $\mathrm{NaOCl}$ for $20 \mathrm{~min}$.

\section{Effects of $\mathrm{HgCl}_{2}$ in combination with preculture treatment and leaf developmental stage}

Table 2 shows the effects of different treatments of $\mathrm{HgCl}_{2}$ on survival of explants derived from the three leaf developmental stages of preculture and non-preculture treated plants. The survival of explants was noticeably high (42.59\%) for explants derived from the stable green leaf stage of preculture treated plants whereas the highest survival was only $27.77 \%$ for explants derived from the stable green leaf stage of non-preculture treated plants, both after sterilization in $0.1 \%$ of $\mathrm{HgCl}_{2}$ for $10 \mathrm{~min}$. Meanwhile the highest survival recorded for explant derived from the bronze leaf stage of preculture treated plants was $38.88 \%$ after sterilization in $0.1 \%$ of $\mathrm{HgCl}_{2}$ for $10 \mathrm{~min}$, while the highest from the bronze leaf stage of non-peculture treated plants was $37.03 \%$ survival after immersion in $0.1 \%$ of $\mathrm{HgCl}_{2}$ for $5 \mathrm{~min}$. In the case of explants derived from the light green leaf stage of preculture treated plants the highest survival was $31.47 \%$, while the highest survival of explants taken from the light green leaf stage of non-preculture treated plants reached only $18.51 \%$, both after exposure to $0.2 \%$ of $\mathrm{HgCl}_{2}$ for $5 \mathrm{~min}$.

\section{Effects of Nano silver in combination with preculture} treatment and leaf developmental stage

Table 3 shows the effects of different treatments of NS on survival of explants from the three leaf developmental stages of preculture and non-preculture treated plants. It is very clear that explants derived from the light green and bronze leaf stages of preculture and nonpreculture treated plants generally showed high survival. Increase in the concentration of NS and duration of immersion decreased the percentage of survival of explants from all three leaf developmental stages of preculture and non-preculture treated plants. The survival of explants from the light green leaf stage reached $94.44 \%$ for preculture treated plants and $88.88 \%$ for non-preculture treated plants after sterilization in $10 \mathrm{ppm}$ of NS for $20 \mathrm{~min}$. Explants taken from the bronze leaf stage of preculture treated plants attained the highest survival of $85.18 \%$ following immersion in $10 \mathrm{ppm}$ of NS for $5 \mathrm{~min}$, while explants from the bronze leaf stage of non-preculture treated plants reached $77.77 \%$ of survival after sterilization in $10 \mathrm{ppm}$ NS for $20 \mathrm{mim}$. Explants from the stable green leaf stage of preculture treated plants could also attain $77.77 \%$ survival after sterilization in $50 \mathrm{ppm}$ of NS for $20 \mathrm{~min}$. This study revealed that NS was more potent than $\mathrm{NaOCl}$ and $\mathrm{HgCl}_{2}$ for effective disinfection of field-derived shoot tip and axillary bud explants of $H$. brasiliensis.

\section{Control of browning of in vitro cultures of $\boldsymbol{H}$. brasiliensis}

Figure 3 shows that the effect of $\mathrm{AgNO}_{3} \mathrm{AC}$ and NS in controlling the browning of in vitro cultures of $H$. brasiliensis after 5 weeks of culture. NS at $4 \mathrm{ppm}$ significantly produced the highest percentage of explant survival (87.03\%) with a low percentage of browning (10\%). In contrast, explants cultured on solid MS medium supplemented with 2 ppm $\mathrm{AgNO}_{3}$ showed the highest percentage of browning (70\%) compared to the rest of the treatments. The present study also showed that NS at $12 \mathrm{ppm}$ and $16 \mathrm{ppm}$ could totally prevent the incidence of in vitro browning of Hevea explants but with significant reduction in the survival of explants compared to NS at $4 \mathrm{ppm}$. Figure $4 \mathrm{~A}$ shows shoot of $H$. brasiliensis free of contamination and browning

\section{Effects of basal medium and sucrose concentration on shoot induction}

The results showed poor shoot formation (18\%) on WPM medium with $6 \%$ sucrose. Meanwhile, there was no shoot formation on WPM medium with $3 \%$ and $9 \%$ sucrose and MS medium at all concentrations of sucrose tested (Figure 5). On the contrary, there was $80 \%$ shoot formation on $\mathrm{MB}$ medium supplemented with $6 \%$ sucrose, which differed significantly compared to the other treatments. This was followed by $34 \%$ shoot induction on MB medium with $9 \%$ sucrose and $28 \%$ on $\mathrm{MB}$ medium with $3 \%$ sucrose. It can clearly be seen that MB medium was most effective on induction of shoots from the fieldderived $H$. brasiliensis explants compared to WPM and MS medium, with the percentage of shoot formation being most enhanced in the presence of $6 \%$ sucrose Figure $4 \mathrm{~B}$ shows healthy and well- formed regenerants on $\mathrm{MB}$ medium supplemented with $6 \%$ sucrose.

\section{Discussion}

A successful tissue culture initiation step often begins with an effective explant sterilization technique and in the micropropagation of 
Citation: Moradpour M, Aziz MA, Abdullah SNA (2016) Establishment of in vitro Culture of Rubber (Hevea brasiliensis) from Field-derived Explants: Effective Role of Silver Nanoparticles in Reducing Contamination and Browning. J Nanomed Nanotechnol 7: 375. doi:10.4172/21577439.1000375

Page 4 of 7

\begin{tabular}{|c|c|c|c|c|c|c|c|}
\hline \multirow{3}{*}{ Time (min) } & \multirow{3}{*}{$\begin{array}{c}\mathrm{NaOCI} \\
\text { concentration (\%) }\end{array}$} & \multicolumn{6}{|c|}{ Mean percentage of explant survival } \\
\hline & & \multicolumn{2}{|c|}{ Bronze Leaf Stage } & \multicolumn{2}{|c|}{ Light Green Leaf Stage } & \multirow{2}{*}{$\begin{array}{c}\text { Stable Green Leaf } \\
\text { Stage } \\
\text { Control }\end{array}$} & \multirow[b]{2}{*}{ Preculture } \\
\hline & & Control & Preculture & Control & Preculture & & \\
\hline Control & Control & $0.0 \pm 0.0 f$ & $1.85 \pm 3.2^{h}$ & $0.0 \pm 0.0^{d}$ & $5.55 \pm 5.55^{9}$ & $0.0 \pm 0.0^{\circ}$ & $3.7 \pm 3.2^{\mathrm{e}}$ \\
\hline \multirow[t]{4}{*}{10} & 10 & $33.32 \pm 5.55^{\text {bef }}$ & $44.44 \pm 5.56^{\text {cde }}$ & $1.85 \pm 3.2^{\mathrm{d}}$ & $11.10 \pm 5.55^{\mathrm{fg}}$ & $9.25 \pm 6.41^{\text {de }}$ & $5.55 \pm 5.55^{\mathrm{e}}$ \\
\hline & 20 & $40.73 \pm 3.21^{b}$ & $49.99 \pm 5.55^{\mathrm{bcd}}$ & $11.10 \pm 5.55^{c}$ & $16.66 \pm 5.55^{\text {ef }}$ & $9.25 \pm 6.41^{\text {de }}$ & $18.51 \pm 3.2^{\mathrm{cd}}$ \\
\hline & 30 & $31.47 \pm 8.48^{\mathrm{bcd}}$ & $53.7 \pm 3.2^{\mathrm{bc}}$ & $16.66 \pm 5.55^{c}$ & $24.07 \pm 3.2^{\mathrm{de}}$ & $12.96 \pm 13.97^{\mathrm{cd}}$ & $22.22 \pm 11.11^{\mathrm{c}}$ \\
\hline & 40 & $16.66 \pm 5.55^{\mathrm{e}}$ & $33.32 \pm 5.55^{f}$ & $12.96 \pm 3.2^{c}$ & $33.32 \pm 5.55^{\mathrm{bc}}$ & $22.21 \pm 5.55^{\mathrm{bc}}$ & $24.07 \pm 3.2^{c}$ \\
\hline \multirow[t]{4}{*}{20} & 10 & $37.03 \pm 3.2^{\mathrm{bcd}}$ & $55.55 \pm 5.55^{\mathrm{b}}$ & $29.62 \pm 3.2^{\mathrm{b}}$ & $38.88 \pm 5.55^{b}$ & $29.62 \pm 3.21^{b}$ & $38.88 \pm 5.55^{b}$ \\
\hline & 20 & $57.40 \pm 3.21^{\mathrm{a}}$ & $79.62 \pm 3.21^{\mathrm{a}}$ & $51.85 \pm 3.2^{\mathrm{a}}$ & $55.55 \pm 5.55^{\mathrm{a}}$ & $51.85 \pm 3.2^{\mathrm{a}}$ & $62.96 \pm 3.2^{\mathrm{a}}$ \\
\hline & 30 & $38.88 \pm 5.55^{\mathrm{bc}}$ & $46.29 \pm 3.21^{\text {bcde }}$ & $27.77 \pm 5.55^{\mathrm{b}}$ & $49.99 \pm 5.55^{\mathrm{a}}$ & $27.77 \pm 5.55^{b}$ & $44.44 \pm 5.56^{b}$ \\
\hline & 40 & $27.77 \pm 5.55^{\mathrm{d}}$ & $33.32 \pm 5.55^{\uparrow}$ & $11.10 \pm 5.55^{\circ}$ & $16.66 \pm 5.55$ & $16.66 \pm 5.55^{\text {cd }}$ & $22.21 \pm 5.55^{\mathrm{c}}$ \\
\hline \multirow[t]{4}{*}{30} & 10 & $29.62 \pm 8.48^{\mathrm{cd}}$ & $38.88 \pm 5.55^{\text {ef }}$ & $24.07 \pm 3.2^{b}$ & $37.03 \pm 3.2^{b}$ & $12.96 \pm 3.2^{\text {cd }}$ & $38.88 \pm 0.0^{b}$ \\
\hline & 20 & $33.32 \pm 5.55^{\mathrm{bcd}}$ & $42.59 \pm 8.48^{\text {def }}$ & $12.96 \pm 3.2^{\mathrm{d}}$ & $25.92 \pm 3.2^{\mathrm{cd}}$ & $20.36 \pm 3.21^{\mathrm{bcd}}$ & $27.77 \pm 5.55^{\circ}$ \\
\hline & 30 & $27.77 \pm 5.55^{d}$ & $33.32 \pm 5.55^{f}$ & $0.0 \pm 0.0^{d}$ & $12.96 \pm 3.2^{\mathrm{fg}}$ & $11.10 \pm 5.55^{\mathrm{cd}}$ & $5.55 \pm 5.55^{e}$ \\
\hline & 40 & $11.10 \pm 5.55^{\mathrm{e}}$ & $22.21 \pm 5.55^{9}$ & $1.85 \pm 3.2^{\mathrm{d}}$ & $5.55 \pm 5.5^{9}$ & $12.96 \pm 3.2^{\mathrm{cd}}$ & $11.10 \pm 5.55^{\mathrm{de}}$ \\
\hline
\end{tabular}

Table 1: Effects of $\mathrm{NaOCl}$, preculture treatment and leaf developmental stage on percentage of survival of $H$. brasiliensis explants after 4 weeks of culture. Means followed by the same letter in the same column are not significantly different based on DMRT $(p=0.05)$.

\begin{tabular}{|c|c|c|c|c|c|c|c|}
\hline \multirow{3}{*}{ Times (min) } & \multirow{3}{*}{$\frac{\mathrm{HgCl}_{2}}{\text { Concentration (\%) }}$} & \multicolumn{6}{|c|}{ Mean percentage of explant survival } \\
\hline & & \multicolumn{2}{|c|}{ Bronze Leaf Stage } & \multicolumn{2}{|c|}{ Light Green Leaf Stage } & \multicolumn{2}{|c|}{ Stable Green Leaf Stage } \\
\hline & & Control & Preculture & Control & Preculture & Control & Preculture \\
\hline Control & Control & $0.0 \pm 0.0^{d}$ & $5.55 \pm 5.55^{b}$ & $0.0 \pm 0.0^{c}$ & $1.85 \pm 3.2^{c}$ & $0.0 \pm 0.0^{c}$ & $0.0 \pm 0.0^{c}$ \\
\hline \multirow[t]{2}{*}{5} & 0.1 & $37.03 \pm 3.2^{\mathrm{a}}$ & $24.07 \pm 23.13^{\mathrm{ab}}$ & $14.81 \pm 3.2^{\mathrm{ab}}$ & $27.77 \pm 0.0^{\mathrm{a}}$ & $11.10 \pm 5.55^{b}$ & $25.92 \pm 3.20^{b}$ \\
\hline & 0.2 & $24.07 \pm 3.2^{b}$ & $18.52 \pm 6.41^{\mathrm{ab}}$ & $18.51 \pm 3.21^{\mathrm{a}}$ & $31.47 \pm 8.48^{a}$ & $22.21 \pm 5.55^{\mathrm{a}}$ & $20.36 \pm 3.21^{b}$ \\
\hline \multirow[t]{2}{*}{10} & 0.1 & $12.96 \pm 3.2^{c}$ & $38.88 \pm 24.21^{\mathrm{a}}$ & $11.10 \pm 5.55^{b}$ & $27.77 \pm 5.55^{a}$ & $27.77 \pm 5.55^{\mathrm{a}}$ & $42.59 \pm 8.48^{a}$ \\
\hline & 0.2 & $0.0 \pm 0.0^{d}$ & $1.85 \pm 3.2^{\mathrm{b}}$ & $1.85 \pm 3.2^{\mathrm{c}}$ & $14.81 \pm 6.41^{b}$ & $5.55 \pm 5.55^{\mathrm{bc}}$ & $5.55 \pm 5.55^{c}$ \\
\hline
\end{tabular}

Table 2: Effects of $\mathrm{HgCl}_{2}$, preculture treatment and leaf developmental stage on percentage of survival of $H$. brasiliensis explants after 4 weeks of culture. Means followed by the same letter in the same column are not significantly different based on DMRT $(p=0.05)$.

\begin{tabular}{|c|c|c|c|c|c|c|c|}
\hline \multirow{3}{*}{ Times (min) } & \multirow{3}{*}{$\begin{array}{l}\text { NS concentration } \\
(p p m)\end{array}$} & \multicolumn{6}{|c|}{ Mean percentage of explant survival (\%) } \\
\hline & & \multicolumn{2}{|c|}{ Bronze Leaf Stage } & \multirow{2}{*}{$\begin{array}{c}\text { Light Green Leaf } \\
\text { Stage }\end{array}$} & \multirow[b]{2}{*}{ Preculture } & \multicolumn{2}{|c|}{ Stable Green Leaf Stage } \\
\hline & & Control & Preculture & & & Control & Preculture \\
\hline Control & Control & $0.0 \pm 0.0^{f}$ & $0.0 \pm 0.0^{i}$ & $0.0 \pm 0.0^{\mathrm{h}}$ & $0.0 \pm 0.0^{\mathrm{h}}$ & $0.0 \pm 0.0^{\mathrm{h}}$ & $0.0 \pm 0.0^{\mathrm{h}}$ \\
\hline \multirow[t]{5}{*}{5} & 2.5 & $49.99 \pm 11.11^{\text {cd }}$ & $55.55 \pm 5.55^{f}$ & $33.32 \pm 5.55^{\mathrm{ef}}$ & $46.29 \pm 3.21^{\mathrm{e}}$ & $16.66 \pm 5.55^{9}$ & $22.21 \pm 5.55^{g}$ \\
\hline & 5 & $61.11 \pm 11.11^{\mathrm{bc}}$ & $66.66 \pm 5.55^{\text {de }}$ & $40.73 \pm 3.21^{\text {de }}$ & $66.66 \pm 5.55^{\mathrm{cd}}$ & $22.21 \pm 5.55^{\mathrm{fg}}$ & $35.18 \pm 3.2^{\text {ef }}$ \\
\hline & 10 & $66.66 \pm 11.11^{\mathrm{ab}}$ & $85.18 \pm 8.48^{a}$ & $44.44 \pm 5.5^{d}$ & $90.73 \pm 8.48^{a}$ & $33.32 \pm 5.55^{\mathrm{cd}}$ & $46.29 \pm 3.21^{\mathrm{cd}}$ \\
\hline & 50 & $75.92 \pm 13.97^{\mathrm{ab}}$ & $81.47 \pm 6.41^{\mathrm{ab}}$ & $62.96 \pm 3.2^{\mathrm{bc}}$ & $77.77 \pm 5.55^{\mathrm{b}}$ & $38.88 \pm 5.55^{c}$ & $49.99 \pm 5.55^{c}$ \\
\hline & 200 & $61.10 \pm 5.55^{\mathrm{bc}}$ & $72.21 \pm 5.55^{\mathrm{bcd}}$ & $38.88 \pm 5.55^{\mathrm{de}}$ & $49.99 \pm 5.55^{\mathrm{e}}$ & $38.88 \pm 5.55^{c}$ & $51.85 \pm 3.2^{\mathrm{c}}$ \\
\hline \multirow[t]{5}{*}{20} & 2.5 & $62.96 \pm 3.20^{\mathrm{abc}}$ & $64.81 \pm 3.2^{\text {def }}$ & $55.55 \pm 5.55^{c}$ & $61.10 \pm 5.55^{d}$ & $29.62 \pm 3.21^{\text {def }}$ & $33.32 \pm 5.55^{\text {ef }}$ \\
\hline & 5 & $68.51 \pm 8.48^{\mathrm{ab}}$ & $72.21 \pm 5.55^{\mathrm{bcd}}$ & $61.10 \pm 5.55^{b c}$ & $66.66 \pm 5.55^{\mathrm{cd}}$ & $31.47 \pm 3.21^{\text {cde }}$ & $38.88 \pm 5.55^{\text {de }}$ \\
\hline & 10 & $77.77 \pm 5.55^{\mathrm{a}}$ & $77.77 \pm 5.55^{\mathrm{abc}}$ & $88.88 \pm 5.55^{a}$ & $94.44 \pm 5.56^{\mathrm{a}}$ & $51.85 \pm 3.2^{\mathrm{b}}$ & $70.36 \pm 3.21^{a}$ \\
\hline & 50 & $64.81 \pm 8.48^{\mathrm{abc}}$ & $61.10 \pm 5.55^{\mathrm{ef}}$ & $44.44 \pm 5.56^{d}$ & $66.66 \pm 5.55^{\mathrm{cd}}$ & $53.7 \pm 3.2^{\mathrm{b}}$ & $77.77 \pm 5.55^{\mathrm{a}}$ \\
\hline & 200 & $18.51 \pm 3.21^{\mathrm{e}}$ & $18.51 \pm 3.21^{h}$ & $27.77 \pm 5.55^{\mathrm{fg}}$ & $44.44 \pm 5.56^{\mathrm{ef}}$ & $66.66 \pm 5.55^{a}$ & $61.10 \pm 5.55^{b}$ \\
\hline \multirow[t]{5}{*}{60} & 2.5 & $64.81 \pm 3.20^{\mathrm{abc}}$ & $66.66 \pm 5.55^{\mathrm{de}}$ & $44.44 \pm 5.56^{d}$ & $66.66 \pm 5.55^{\mathrm{cd}}$ & $24.07 \pm 3.2^{\text {efg }}$ & $27.77 \pm 5.55^{f g}$ \\
\hline & 5 & $68.51 \pm 6.41^{\mathrm{ab}}$ & $68.51 \pm 6.41^{\text {cde }}$ & $57.40 \pm 3.21^{c}$ & $72.21 \pm 5.55^{\mathrm{bc}}$ & $24.06 \pm 6.41^{\text {efg }}$ & $38.88 \pm 5.55$ de \\
\hline & 10 & $61.11 \pm 11.11^{\mathrm{bc}}$ & $66.66 \pm 5.55^{\mathrm{de}}$ & $66.66 \pm 5.55^{b}$ & $75.92 \pm 3.2^{\mathrm{bc}}$ & $49.99 \pm 5.55^{b}$ & $44.44 \pm 5.56^{\mathrm{cd}}$ \\
\hline & 50 & $38.88 \pm 11.11^{d}$ & $44.44 \pm 5.56^{9}$ & $22.21 \pm 5.55^{g}$ & $37.03 \pm 3.2^{f}$ & $29.62 \pm 3.21^{\text {def }}$ & $44.44 \pm 5.56^{\mathrm{cd}}$ \\
\hline & 200 & $0.0 \pm 0.0^{f}$ & $0.0 \pm 0.0^{i}$ & $0.0 \pm 0.0^{\mathrm{h}}$ & $16.66 \pm 5.55^{g}$ & $5.55 \pm 5.55^{h}$ & $3.7 \pm 6.41^{\mathrm{h}}$ \\
\hline
\end{tabular}

Table 3: Effects of NS, preculture treatment and leaf developmental stage on percentage of survival of $H$. brasiliensis explants after 4 weeks of culture. Means followed by the same letter in the same column are not significantly different based on DMRT $(p=0.05)$.

H. brasiliensis the establishment of an axenic culture is one of the most challenging steps. In this study, $\mathrm{NaOCl}, \mathrm{HgCl}_{2}$ and $\mathrm{NS}$ were assessed as sterilants on explants derived from different leaf developmental stages of preculture and non-preculture treated plants of $\mathrm{H}$. brasiliensis. The use of increasing strength of $\mathrm{NaOCl}$ and $\mathrm{HgCl}_{2}$ or extending the time of immersion in the sterilants resulted in the loss of explants due to browning followed by leaching of chlorophyll from the explants. The results indicated the necessity of using the correct concentration and immersion time in $\mathrm{NaOCl}$ and $\mathrm{HgCl}_{2}$ as well as a suitable leaf developmental stage and with preculture treatment in order to overcome the contamination of $H$. brsiliensis explants in vitro. Debergh and Maene [15] proposed a scheme focusing on the preculture phase to obtain 
Citation: Moradpour M, Aziz MA, Abdullah SNA (2016) Establishment of in vitro Culture of Rubber (Hevea brasiliensis) from Field-derived Explants: Effective Role of Silver Nanoparticles in Reducing Contamination and Browning. J Nanomed Nanotechnol 7: 375. doi:10.4172/21577439.1000375

Page 5 of 7

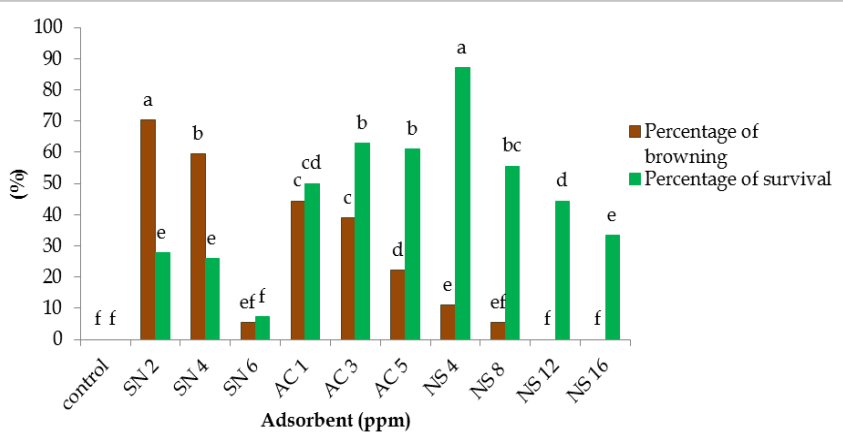

Figure 3: Effects of different adsorbents on control of browning of in vitro culture of $H$. brasiliensis after 5 weeks of culture. Values represent means for 18 explants per treatment per replication. The same letters represent no significant difference between treatments according to one-way analysis of variance $(P=0.05)$
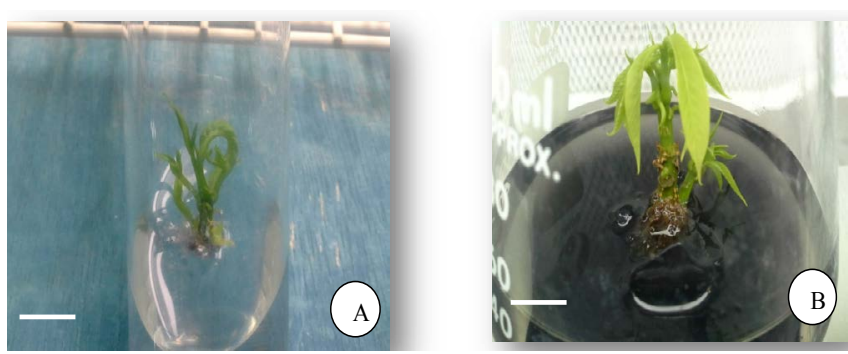

Figure 4: $\mathrm{H}$. brasiliensis shoots after NS treatment $(\mathrm{bar}=0.75 \mathrm{~cm}),(\mathrm{A})$ shoot without contamination and browning (bar $=0.28 \mathrm{~cm}),(B)$ healthy and wellformed regenerants $($ bar $=0.75 \mathrm{~cm})$.

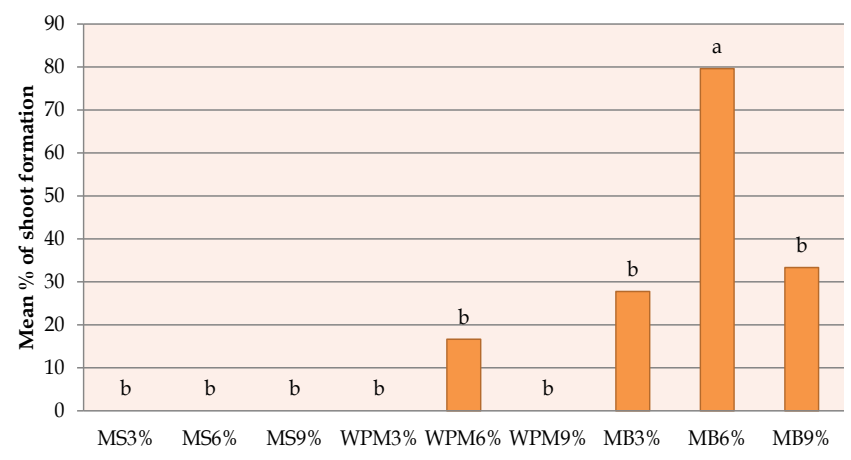

Treatment

Figure 5: Effects of basal medium and sucrose concentration on shoot induction of $H$. brasiliensis explants after 16 weeks of culture. Medium formulations: MS, WPM and MB; Sucrose concentrations: $3 \%, 6 \%$ and $9 \%$. Values represent means for 18 explants per treatment per replication. The same letters represent no significant difference between treatments according to one-way analysis of variance $(P=0.05)$.

healthier explants and uniform responses. Growth, morphogenesis and rates of propagation in vitro can be improved by applying appropriate environmental and chemical pretreatments to the stock plants. To our knowledge, there are no reports so far investigating on the effects of $\mathrm{NaOCl}$ and $\mathrm{HgCl}_{2}$ in combination with leaf developmental stage and preculture treatment on overcoming contamination of field-derived explants of $H$. brasiliensis. In the assessment of NS as a sterilant, the results revealed that it was more effective than $\mathrm{NaOCl}$ and $\mathrm{HgCl}_{2}$ in reducing contamination of $H$. brasiliensis explants. Increasing the strength of NS or extending the time of immersion in the sterilant did not cause browning and leaching of chlorophyll from the explants. The highest percentage of survival (94.44\%) was attained when explants derived from the light green leaf stage of preculture treated plants were sterilized in $10 \mathrm{ppm}$ of NS for $20 \mathrm{~min}$. Chen and Schluesener [16], Mahna et al. [17] and Razali et al. [18] also suggested the use of NS for disinfection of in vitro plant species they worked on. Abdi et al. [14] and Abdi [19] reported on the application of 100 ppm NS for 60 min as the most effective decontamination procedure for Valeriana officinalis explants. However in this study, a low concentration of $10 \mathrm{ppm}$ NS at an immersion time of 20 min was highly effective in reducing microbial contamination and increasing the survival of $H$. brasiliensis explants. The mechanism of action of NS in terminating the microorganisms is not known clearly. However, it has been shown that NS releases silver ions $\left(\mathrm{Ag}^{+}\right)$slowly which can destroy the cell structure of microorganisms [20]. Dibrov et al. [21] stated that the effects of $\mathrm{Ag}^{++}$ on microorganisms may be due to their chemosmotic activity. These researchers showed that $\mathrm{Ag}^{+}$affects the phospholipids and destroy the cell membrane of microorganisms. $\mathrm{Ag}^{+}$also may substitute the sulphur in the $-\mathrm{SH}$ groups of cell membrane of microorganisms and destroy them. The destructive effects of $\mathrm{Ag}^{+}$are related to the production of active silver containing organic compounds. These compounds can attract the microorganisms and destroy their structure. The use of nano-sized silver particles as antimicrobial agent has become more common as technological advances make their production more economical. One of the potential applications of silver is in the management of plant diseases. Since silver displays multiple modes of inhibitory action on microorganisms, it may be used for controlling various plant pathogens in a relatively safer way compared to synthetic fungicides [22]. Results obtained in this study including the overall low percentage of microbial contamination of explants derived from the different phenological stages after sterilization in NS reconfirmed the antifungal activity of NS as reported by Jo et al. [22].

Another most frequently encountered problem during micropropagation of $H$. brasiliensis is the occurrence of browning. Several authors have reported on methods of controlling phenolic compounds exudation from the species [23-25]. This study revealed the effectiveness of nano silver particles as an antioxidant and polyphenol adsorbent compared to silver nitrate and activated charcoal on explants of $H$. brasiliensis. Earlier investigations revealed that the dark exudate was very difficult to eradicate by pretreatment washes [26]. Ziv and Halvey [27] found that phenoloic compounds inhibited shoot formation in Strelitzia reginae and Geranium species and also caused browning and necrosis of Kangarof paws. Reports have shown that in other woody species when activated charcoal was added to the medium, with or without dark periods at the beginning of the experiment, it eliminated browning and was beneficial to shoot formation $[28,29]$. However, in our study on rubber though the explant survival reached $65 \%$ in the presence of $3 \mathrm{ppm}$ activated charcoal the percentage of browning was still high at $40 \%$. Meanwhile, evaluation on effects of $\mathrm{AgNO}_{3}$ showed even higher percentage of browning (70\%) with an explant survival of less than $30 \%$ upon application of $2 \mathrm{ppm} \mathrm{AgNO}_{3}$. Earlier, Housti [10] reported that $\mathrm{AgNO}_{3}$ showed only a slight positive effect on organogenesis of $H$. brasiliensis and a very slight antibrowning effect on callus of this species. It was also evident from our study that shoots of $H$. brasiliensis produced in the presence of activated charcoal and silver nitrate were not vigorous and showed symptoms of chlorosis. Interestingly, our study shows that nano silver is highly effective on the explant survival, behaviour and response to organogenesis. Transmission electron microscopy (TEM) images (Figure 6) of the silver nanoparticles used in this study indicated the 
Citation: Moradpour M, Aziz MA, Abdullah SNA (2016) Establishment of in vitro Culture of Rubber (Hevea brasiliensis) from Field-derived Explants: Effective Role of Silver Nanoparticles in Reducing Contamination and Browning. J Nanomed Nanotechnol 7: 375. doi:10.4172/21577439.1000375

Page 6 of 7
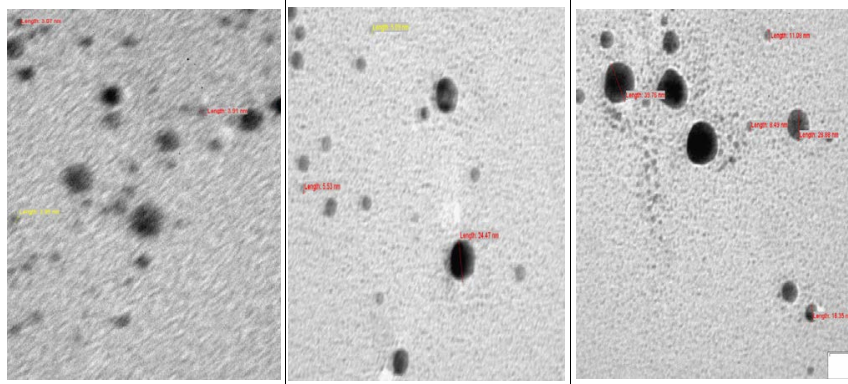

Figure 6: Transmission electron microscopy (TEM) image of silver nanoparticles. Scale bars: 50, 100 and $200 \mathrm{~nm}$.

extremely minute size of the particles. A study by Zhang et al. [30] reported that $\mathrm{Ag}+$ release rates were found to depend on the primary particle size and concentration of NS, when other environmental factors (e.g. dissolved oxygen and protons) were kept constant.. To our knowledge, there are no reports so far investigating the effects of nano silver as an antioxidant and polyphenol adsorbent in overcoming browning of field-derived H. brasiliensis explants.

In this study, MB medium was comparatively found to be more suitable than WPM and MS media on in vitro shoot induction of $H$. brasiliensis. MB medium had earlier been specifically suggested for in vitro culture of Hevea by Enjalric and Carron [31]. There are numerous reports on the better performance of woody plant species grown on low salt media including WPM, however it was not ideally the case with $H$. brasiliensis. This study showed that the mean percentage of shoot formation from cultures grown on MB medium supplemented with $3 \%, 6 \%$ and $9 \%$ sucrose was better than that obtained on WPM with $6 \%$ sucrose. WPM contains much less macro elements in comparison with MB medium. Earlier, Seneviratne et al. [32] showed better growth and survival of $H$. brasiliensis axillary bud on WPM supplemented with $10 \%$ sucrose in comparison with MS medium [33-35].

\section{Conclusion}

This research study indicates that the successful establishment of invitro culture of $H$. brasiliensis requires the understanding of the species leaf developmental stages, the interaction of the explant source with the environment and the effective application of the non-toxic silver nano particles in reducing microbial contamination and browning of Hevea explants. An efficient initial culture establishment developed in this study thus opens the way for future application of the microcutting technique for propagation as well as genetic improvement of $H$. brasiliensis.

\section{Acknowledgements}

The authors are thankful to the Department of Agriculture Technology, Faculty of Agriculture, for the laboratory facilities provided.

\section{References}

1. Hua YW, Huang TD, Huang $H$ (2010) Micropropagation of self-rooting juvenile clones by secondary somatic embryogenesis in Hevea brasiliensis. Plant Breeding 129: 202-207.

2. Carron MP, DAuzac J (1992) Biochemical and histological features of somatic embryogenesis in Hevea brasiliensis. Indian J Natural Rubber Res 5: 7-17.

3. Thulaseedharan A, Jayasree PK, Venkatachalam P (2000) Biotechnological approaches for crop improvement in rubber. In: Biotechnology in Horticultural and Plantation Crops. Malhotra Publishing House New Delhi 323-351.

4. Lardet L, Enjalric F, Carron MP (1990) Culture d'apex d'Hevea brasiliensis (Mull. Arg.). Influence du stade morphogenetique et de l'age des explants. Comptes Rendus de l'Académie des Sciences Paris 310: 195-202.
5. Perrin Y, Lardet L, Enjalric F, CarronMP (1994) Rajeunissement de clones matures d'Hevea brasiliensis (Müll.Arg.) parmicrogreffage in vitro. Can J Plant Sci 74: 623-630.

6. Bonga, JM (1982) Vegetative propagation in relation to juvenility, maturity and rejuvenation. In Tissue Culture in Forestery. Springer 387-412.

7. Hackett WP (1985) Juvenility, maturation and rejuvenation in woody plants Hortic Rev 7: 109-155.

8. Monteuuis O (1989) Maturation concept and possible rejuvenation of arborescent species. Limits and promises of shoot apical meristems to ensure successful cloning. In Breeding Tropical Trees: Population Structure and Genetic Improvement Strategies in Clonal and Seedling Forestry Winrock International 106-118.

9. von Aderkas $P$, Bonga JM (2000) Influencing micropropagation and somatic embryogenesis in mature trees by manipulation of phase change, stress and culture environment. Tree Physiol 20: 921-928.

10. Housti F, Coupe M, d'Auzac J (1992) Browning mechanisms and factors of influence in in vitro Hevea calli cultures. Indian J Natural Rubber Res 5: 1-2.

11. Mederos-Molina S, Trujillo MI (1999) Elimination of browning exudate and in vitro development of shoots in Pistacia vera L. cv. Mateur and Pistacia atlantica Desf. Culture. Acta Societatis Botanicorum Poloniae, 68: 21-24.

12. Silver S, Phung LT (1996) Bacterial heavy metal resistance: new surprises. Annu Rev Microbiol 50: 753-789.

13. Sondi I, Salopek-Sondi B (2004) Silver nanoparticles as antimicrobial agent: a case study on E. coli as a model for Gram-negative bacteria. J Colloid Interface Sci 275: 177-182.

14. Abdi G, Salehi H, Khosh-Khui M (2008) Nano silver: a novel nanomaterial for removal of bacterial contaminants in valerian (Valeriana officinalis L.) tissue culture. Acta Physiol Plant 30: 709-714

15. Debergh PC, Maene LJ (1981) A scheme for commercial propagation of ornamental plants by tissue culture. Scientia Hortic 14: 335-345.

16. Chen X Schluesener HJ (2008) Nanosilver: a nanoproduct in medical application. Toxicol Lett 176: 1-12.

17. Mahna N, Vahed SZ, Khani S (2013) Plant in vitro culture goes nano: nanosilvermediated decontamination of ex vitro explants. J Nanomed and Nanotechnol.

18. Razali M, Nur Aida MP, Habsah M, Hairiyah M, Rohaya MA, et al. (2012) Influence of nanosilver packaging on quality retention of peeled garlic. In VII International Postharvest Symposium 1012: 1317-1322.

19. Abdi G (2012) Evaluation on the potential of Nano silver for removal of bacterial contaminants in valerian (Valeriana officinalis L.) tissue culture. J Biol Environ Sci 6: 199-205.

20. Lubick N (2008) Nanosilver toxicity: ions, nanoparticles--or both? Environ Sci Technol 42: 8617.

21. Dibrov P, Dzioba J, Gosink KK, Häse CC (2002) Chemiosmotic mechanism of antimicrobial activity of $\mathrm{Ag}(+)$ in Vibrio cholerae. Antimicrob Agents Chemother 46: 2668-2670.

22. Jo YK, Kim BH, Jung G (2009) Antifungal activity of silver ions and nanoparticles on phytopathogenic fungi. Plant Dis 93: 1037-1043.

23. Enjalric F, Carron MP, Lardet L (1987) Contamination of primary cultures in tropical areas: the case of Hevea brasiliensis. Bacterial and Bacteria-like Contaminants of Plant Tissue Cultures 225: 57-66.

24. Seneviratne P, Wijesekara GAS (1996) The problem of phenolic exudates in in vitro cultures of mature Hevea brasiliensis. J Plantation Crops 24: 54-62.

25. Sirisom Y, Te-chato S (2012) The effect of peptone and silver nitrate on in vitro shoot formation in Hevea brasiliensis Muell Arg. J Agric Technol 8: 1509-1516.

26. Barghchi M, Alderson PG (1985) In vitro propagation of Pistacia vera L. and the commercial cultivars Ohadi and Kalleghochi. J Hortic Sci 60: 423-430.

27. Ziv M, Halevy AH (1983) Control of oxidative browning and in vitro propagation of Strelitzia reginae. HorticSci 18: 434-436.

28. George EF (1996) Plant propagation by tissue culture. Part 2. Exegetics Ltd Hardcover USA.

29. Gamborg O, Phillips G (1995) Plant cell, tissue and organ culture: fundamental methods. Springer-Verlag, Heidelberg, New York, USA. 
Citation: Moradpour M, Aziz MA, Abdullah SNA (2016) Establishment of in vitro Culture of Rubber (Hevea brasiliensis) from Field-derived Explants: Effective Role of Silver Nanoparticles in Reducing Contamination and Browning. J Nanomed Nanotechnol 7: 375. doi:10.4172/21577439.1000375

30. Zhang W, Yao Y, Sullivan N, Chen Y (2011) Modeling the primary size effects of citrate-coated silver nanoparticles on their ion release kinetics. Environ Sci Technol 45: 4422-4428.

31. Enjalric F, Carron MP (1982) Microbouturage in vitro de jeunes plants d'Hevea brasiliensis (Kunth., Mull. Arg). Comptes Rendus Des Seances de l'Academie Des Science 295: 261-264.

32. Seneviratne P, Flegmann AW, Wijesekera GAS (1996) The effects of the basic medium and the carbohydrate content on shoot cultures of Hevea brasiliensis. J Rubber Res Inst Sri Lanka 78: 60-68.
33. Alderson PG, Dullforce WM (1987) Micropropagation in horticulture, practice and commercial problems. The University of Nottingham Trent Print Unit.

34. Lieberei R1 (2007) South American leaf blight of the rubber tree (Hevea spp.): new steps in plant domestication using physiological features and molecular markers. Ann Bot 100: 1125-1142.

35. Murashige T, Skoog $F$ (1962) A revised medium for rapid growth and bio assays with tobacco tissue cultures. Physiol Plant 15: 473-479. 